University of Wollongong

Research Online

Faculty of Engineering and Information

Faculty of Engineering and Information

Sciences - Papers: Part B

Sciences

2017

A variation focused cluster analysis strategy to identify typical daily heating load profiles of higher education buildings

Zhenjun Ma

University of Wollongong, zhenjun@uow.edu.au

Rui Yan

University of Wollongong, ry721@uowmail.edu.au

Natasa Nord

Norwegian University of Science and Technology

Follow this and additional works at: https://ro.uow.edu.au/eispapers1

Part of the Engineering Commons, and the Science and Technology Studies Commons

Research Online is the open access institutional repository for the University of Wollongong. For further information contact the UOW Library: research-pubs@uow.edu.au 


\title{
A variation focused cluster analysis strategy to identify typical daily heating load profiles of higher education buildings
}

\begin{abstract}
This paper presents a variation focused cluster analysis strategy to identify typical daily heating energy usage profiles of higher education buildings. Different from the existing cluster analysis studies which were primarily developed using Euclidean distance as the dissimilarity measure and tended to group the daily load profiles with similar magnitudes, Partitioning Around Medoids (PAM) clustering algorithm with Pearson Correlation Coefficient-based dissimilarity measure was used in this study to group the daily load profiles on the basis of the variation similarity. A comparison of the proposed strategy with a k-means cluster analysis with Euclidean distance as the dissimilarity measure was also performed. The performance of the proposed strategy was tested and evaluated using the three-year hourly heating energy usage data collected from 19 higher education buildings in Norway. The results demonstrated the effectiveness of the proposed strategy in identifying the typical daily energy usage profiles. The identified typical heating load profiles provided the information such as the peaks and troughs of the daily heating demand, daily high heating demand period and daily load variation. The identified profiles also helped to categorize multiple buildings into different groups in terms of the similar energy usage behaviors to support further energy efficiency initiatives.
\end{abstract}

\section{Disciplines}

Engineering | Science and Technology Studies

\section{Publication Details}

Ma, Z., Yan, R. \& Nord, N. (2017). A variation focused cluster analysis strategy to identify typical daily heating load profiles of higher education buildings. Energy, 134 90-102. 

load profiles of higher education buildings

8 Abstract: This paper presents a variation focused cluster analysis strategy to identify typical 9 daily heating energy usage profiles of higher education buildings. Different from the existing 10 cluster analysis studies which were primarily developed using Euclidean distance as the

11 dissimilarity measure and tended to group the daily load profiles with similar magnitudes,

12 Partitioning Around Medoids (PAM) clustering algorithm with Pearson Correlation Coefficient-

13 based dissimilarity measure was used in this study to group the daily load profiles on the basis of

14 the variation similarity. A comparison of the proposed strategy with a k-means cluster analysis

15 with Euclidean distance as the dissimilarity measure was also performed. The performance of the 16 proposed strategy was tested and evaluated using the three-year hourly heating energy usage data

17 collected from 19 higher education buildings in Norway. The results demonstrated the

18 effectiveness of the proposed strategy in identifying the typical daily energy usage profiles. The

19 identified typical heating load profiles provided the information such as the peaks and troughs of

20 the daily heating demand, daily high heating demand period and daily load variation. The

21 identified profiles also helped to categorize multiple buildings into different groups in terms of

22 the similar energy usage behaviors to support further energy efficiency initiatives. 
23 Keywords: Cluster analysis; Load profile; Pearson Correlation Coefficient; Higher education

24 buildings

\section{Nomenclature}

$26 \quad C \quad$ set of the identified clusters

$27 \quad \operatorname{cov} \quad$ covariance

$28 d$ distance

$29 \quad$ D $\quad$ Dunn index

$30 \quad k \quad$ number of clusters

$31 \quad n \quad$ number of observations

$32 \quad N_{d} \quad$ number of days belongs to a typical daily load profile

$33 N_{d, \max } \quad$ maximum number of days belongs to a typical daily load profile

$34 \quad 0 \quad$ data point identified as a medoid

$35 \quad p \quad$ tail area probability

36 PCC Pearson Correlation Coefficient

$37 \quad q \quad$ data point

$38 \quad R \quad$ studentized deviate

$39 \quad \mathrm{RP} \quad$ relative proportion

$40 \quad t \quad$ t-distribution

$41 \quad X, Y \quad$ vectors

$42 \quad x, y \quad$ values of individual dimension

$43 \quad$ Greek letters

$44 \quad \alpha \quad$ significance level

$45 \lambda \quad$ critical value

$46 \quad \sigma \quad$ standard deviation 
$\phi \quad$ identified clusters

49 ED Euclidean distance

50 PCC Pearson correlation coefficient

\section{1. Introduction}

53 Building energy efficiency is essential for reducing global energy usage and promoting

54 environmental sustainability, as the building sector contributes to a large proportion of the total 55 energy usage worldwide [1, 2]. With the development of automatic meter reading systems, 56 massive high-resolution energy usage data from buildings can now be easily collected with a 57 reasonably low cost [3]. This massive amount of data provides a great opportunity to assist in 58 better understanding building energy usage characteristics and operational performance, and in 59 extracting the useful and hidden information to support the areas including but not limited to 60 building energy performance assessment and benchmarking, building load estimation and 61 demand side management, occupant behavior prediction, and fault detection and diagnosis of 62 heating, ventilation and air-conditioning systems.

63 Identification of typical building load profiles based on the collected massive energy usage 64 data has been proved to be an effective way to understand building energy usage characteristics 65 and help to develop cost effective load shifting and peak demand control strategies [4, 5]. Cluster 66 analysis, as a data mining technique to discover the natural grouping(s) of a set of patterns, points, 67 or objects [6], has been used in a number of studies to identify typical building load profiles [4, 5, 68 7, 8]. Jota et al. [4], for instance, used an agglomerative hierarchical clustering algorithm with

69 Euclidean distance (ED) to identify the typical building load profiles, which were further used to 70 predict the accumulated energy usage at the end of the day and the daily peak demand. Typical 
71 heating load profiles of Danish single-family detached homes were studied by do Carmo and

72 Christensen [5] using the k-means algorithm. Three types of typical load profiles, i.e. high

73 demand, medium demand and low demand, were identified for the buildings operated during

74 weekdays and weekends, respectively. A binary regression analysis was also performed to

75 identify the explanatory factors governing the different heating load profiles. The implementation

76 and evaluation of a cluster analysis approach for smart meter data were reported by Flath et al.

77 [7], in which the k-means algorithm was used to identify typical building daily and weekly load

78 profiles of a business intelligence environment. Symbolic Aggregate approXimation (SAX)

79 method was used by Miller et al. [8] to transform building energy usage data into alphabets while

80 the k-means algorithm was used to identify the typical daily load profiles. Fuzzy c-means (FCM)

81 was adopted by Fernandes et al. [9] to identify the typical gas consumption profiles of residential

82 buildings. It was found that the gas consumption peaks were related to the upper-middle social

83 class with a high income and the highest daytime off-peak gas usage was related to the ageing

84 population. Panapakidis et al. [10] utilized several clustering algorithms, including k-means, k-

85 means ${ }^{++}$, minimum variance criteria, FCM and self-organizing map (SOM), to identify typical

86 building electricity usage profiles. It was concluded that SOM and k-means++ in the frequency

87 domain outperformed the other clustering techniques in terms of the clustering error.

$88 \quad$ Cluster analysis distinguishes data vectors based on a certain type of dissimilarity measures

89 [11]. Although different cluster analysis algorithms have been proposed for different scenarios, to

90 the best knowledge of the authors, the existing studies on the identification of building typical

91 load profiles using cluster analysis were primarily developed using ED as the dissimilarity

92 measure. Cluster analysis using ED-based dissimilarity measure tends to identify the daily load

93 profiles that are similar in terms of the intensity rather than the variation. In other words, the

94 typical daily load profile identified using cluster analysis with ED as the dissimilarity measure is 
95 more related to the load magnitude. For example, do Carmo and Christensen [5] labeled the

96 identified load profiles as high demand, medium demand, and low demand. ED-based

97 dissimilarity measure is also difficult to identify building daily load profiles with similar

98 variations but with different magnitudes, which will be elaborated in Section 2.2.

99 Higher education buildings have an important role in the minimization of greenhouse gas

100 emissions from the built environment and in assisting the mitigation and adaptation of our society

101 to climate change [12]. This paper presents a strategy using Partitioning Around Medoids (PAM)

102 clustering algorithm to identify typical daily heating energy usage profiles of a group of higher

103 education buildings. The novelty of this paper is to use Pearson Correlation Coefficient (PCC) as

104 the dissimilarity measure to cluster daily heating energy usage profiles, in which the typical

105 energy usage profiles are identified based on the load variation instead of the load magnitude,

106 which is different from the majority of the previous studies used cluster analysis with ED as the

107 dissimilarity measure. Based on the identified typical load profiles, a hierarchical clustering was

108 used to group the buildings with similar heating energy usage characteristics. A comparison of

109 the proposed strategy with an ED-based k-means cluster analysis strategy was also performed.

110 The performance of the proposed strategy was evaluated using three-year hourly district heating

111 energy usage data collected from 19 higher education buildings in Norway.

\section{2. Development of the variation focused cluster analysis strategy}

1132.1 Outline of the variation focused cluster analysis strategy

114 The outline of the proposed variation focused cluster analysis strategy is illustrated in Fig. 1,

115 which was developed following the standard Knowledge Discovery from Database (KDD)

116 process [13]. It mainly consisted of four steps, including data collection, data pre-processing, data

117 mining, and results evaluation and interpretation. 
118 The collection of hourly energy usage data of individual buildings was the first step and the

119 necessary data can be generally collected from building management systems. There were four

120 tasks in the data pre-processing step, including outlier removal, data standardization, data

121 segmentation and the removal of the weekend data and the data segments with small variations.

122 In this study, the generalized Extreme Studentized Deviate (ESD) test method was used to

123 identify and remove the outliers in the collected raw data. As the magnitude of the energy usage

124 varied from building to building, to avoid the influence of identifying typical daily energy usage

125 profiles, the processed data of each building was standardized to zero mean and one standard

126 deviation. Data segmentation was then performed to transform the data into 24 hours segments in

127 order to form daily load profiles. As the primary focus of this strategy was to identify the typical

128 daily energy usage profiles during the building occupied periods with distinctive variation

129 patterns, the segments during the weekends and the segments with small variations were

130 discarded. The segments with small variations refer to the segments with a small difference

131 between the daily maximum and minimum energy usages. In this study, a threshold of 5.0\% was

132 used, which means that $5.0 \%$ of the segments with the least difference among all daily segments

133 were discarded.

134 In the data mining step (see Fig. 1), Pearson Correlation Coefficient (PCC) was first

135 calculated to measure the dissimilarities among different daily load profiles. The Partitioning

136 Around Medoids (PAM) clustering algorithm was then applied to cluster the daily load profiles

137 with similar variations based on the PCC-based dissimilarity measure calculated. A boxplot was

138 used to remove the daily load profiles with the large aggregated dissimilarities (i.e. the sum of the

139 dissimilarities to all other daily load profiles in the same cluster) in each cluster, in order to

140 reduce the influence of the extreme daily load profiles on the identification of typical daily load

141 profiles. The daily load profiles with the aggregated dissimilarity measure beyond Q3+1.5IQR, 
142 where Q3 is the third quartile and IQR is an inter-quartile range between Q1 and Q3, were

143 discarded. The typical daily load profiles were then determined by averaging the remaining daily

144 load profiles in each cluster. Lastly, a hierarchical clustering was used to group the buildings with

145 similar load characteristics.

146 In the last step, the identified typical daily load profiles and building groups were visualized,

147 evaluated and interpreted.

$148 \quad 2.2$ Outlier removal with the generalized Extreme Studentized Deviate (ESD) test method

149 Generalized ESD test method has been applied for identifying and removing outliers in 150 building energy usage data in a number of studies [14-16]. This method detects outliers through

151 comparing the studentized deviate $R$ of $n$ extreme observations to a critical value $\lambda$. The extreme

152 observations are the observations with the first $n$ largest differences compared to the mean value

$153 \bar{x}$. The $R_{i}$ of the $i^{\text {th }}$ extreme observation $x_{e, i}$ is determined using Eq. (1) and the corresponding $\lambda_{i}$

154 is defined in Eq. (2) [14]. The generalized ESD test method starts with the most extreme

155 observation and compares its $R_{i}$ to the corresponding $\lambda_{i}$. If $R_{i}$ is greater than $\lambda_{i}$, the extreme

156 observation is then identified as an outlier and removed from the dataset. The same process is

157 applied to the next extreme observation until all the $n$ extreme observations are examined. More

158 details of the generalized ESD test method can be found in [14]. If an outlier is identified and

159 removed, its position will be filled through the linear interpolation.

$$
R_{i}=\frac{\left|x_{e, i}-\bar{x}\right|}{\sigma}
$$

161

$$
\lambda_{i}=\frac{(n-i) t_{n-i-1, p}}{\sqrt{(n-i+1)\left(n-i-1+t_{n-1-1, p}^{2}\right)}}
$$

162 where $\sigma$ is the standard deviation, $t_{n-i-1, p}$ is the t-distribution with $n-i-1$ degrees of freedom and $p$ is 163 the tail area probability and is defined in Eq. (3) [14]. 


$$
p=\frac{\alpha}{2(n-i+1)}
$$

165 where $\alpha$ is the significance level.

1662.3 Pearson Correlation Coefficient (PCC)-based dissimilarity measure

167 Cluster analysis groups the data by minimizing the inter-cluster dissimilarity while 168 maximizing the intra-clusters based on a certain type of the dissimilarity measures [17]. In the 169 proposed strategy, the distance between the two daily load profiles $\left(d_{P C C}\right)$ determined by Eq. (4)

170 was used to measure the dissimilarity between the two daily load profiles, in which the PCC is 171 defined in Eq. (5).

$$
\begin{gathered}
d_{P C C}(X, Y)=1-P C C \\
\operatorname{PCC}(X, Y)=\frac{\operatorname{cov}(X, Y)}{\sigma_{X} \sigma_{Y}}=\frac{\sum_{i=1}^{n}\left(x_{i}-\bar{x}\right)\left(y_{i}-\bar{y}\right)}{\sqrt{\sum_{i=1}^{n}\left(x_{i}-\bar{x}\right)^{2}} \sqrt{\sum_{i=1}^{n}\left(y_{i}-\bar{y}\right)^{2}}}
\end{gathered}
$$

174 where $d$ means the distance, cov stands for the covariance, $X$ and $Y$ represent the vectors, and $x$ 175 and $y$ stands for the values of the individual dimension.

176 A comparison between the use of the PCC-based and ED-based dissimilarity measures is 177 illustrated in Fig. 2, where ED was calculated using Eq. (6). The data used in Fig. 2 was given 178 only for illustration purpose.

$$
d_{E D}(X, Y)=\sqrt{\sum_{i=1}^{n}\left(x_{i}-y_{i}\right)^{2}}
$$

It can be seen that the ED of Profiles 1 and $2\left(\mathrm{~d}_{12}\right)$ and ED of Profiles 1 and $3\left(\mathrm{~d}_{13}\right)$ were $38.91 \mathrm{kWh}$ and $8.178 \mathrm{kWh}$, respectively. Compared to Profile 2, Profile 3 was closer to Profile 1 in terms of the ED dissimilarity measure. However, the variation of Profile 2 was more similar to 183 that of Profile 1, as shown in Fig. 2(a). The PCC of Profiles 1 and 2 (PCC 12$)$ and PCC of Profiles 
1841 and $3\left(\mathrm{PCC}_{13}\right)$ were 0.978 and 0.173 , respectively. A higher PCC indicated a higher similarity

185 between the two profiles in terms of the daily load variation. Therefore, PCC-based dissimilarity

186 measure can better identify the daily load profiles with similar variations.

187 2.4 Partitioning Around Medoids clustering algorithm

188 Partitioning Around Medoids (PAM) clustering algorithm [18] was used to cluster daily load

189 profiles using the PCC-based dissimilarity measure. In PAM, a medoid is a data point in a

190 particular cluster which has a minimized aggregated distance to all other data points in that

191 cluster. The objective of PAM clustering algorithm is to find a subset $\left\{o_{1}, o_{2}, \ldots, o_{k}\right\} \in\left\{q_{1}, q_{2}, \ldots, q_{n}\right\}$

192 which minimizes the objective function as shown in Eq. (7) [18, 19].

$$
\sum_{i=1}^{n} \min _{m=1, \ldots, k} d\left(q_{i}, o_{m}\right)
$$

194 where $n$ is the number of the data points, $k$ is the number of the clusters, $q$ is the data point, and $o$ 195 is the data point identified as a medoid.

196 PAM consists of two major steps, i.e. build and swap. The first step is to build initial medoids

197 by selecting the first medoid as the data point with the minimum sum of the distance to all other

198 points and selecting the subsequent medoids by finding the points which minimize Eq. (7). The

199 second step repeatedly swap $i \in\left\{o_{1}, o_{2}, \ldots, o_{k}\right\}$ with $\mathrm{j} \in\left\{q_{1}, q_{2}, \ldots, q_{n}\right\}$ if the swap decreases the

200 objective significantly until reaching the convergence [18, 19].

201 PAM requires users to provide the number of clusters $k$ as an input parameter. In the 202 proposed strategy, Dunn Index was used to validate the clustering result and determine the 203 optimal value of $k$. Dunn Index is expressed as the ratio of the smallest inter-cluster distance to 204 the largest intra-cluster distance and is defined in Eq. (8) [20].

$$
D(\phi)=\frac{\min _{C_{k}, C_{l} \in \phi, C_{k} \neq C_{l}}\left(\min _{i \in C_{k}, j \in C_{l}} d(i, j)\right)}{\max _{C_{m} \in \phi}\left(\max _{i, j \in C_{m}, i \neq j} d(i, j)\right)}
$$


206 where $C_{k}$ and $C_{l}$ are the clusters belong to the set of the identified clusters $\phi$. A higher Dunn

207 Index means a better clustering result. The optimal number of clusters $k$ was determined based on

208 the highest Dunn Index within the defined range of the number of clusters.

2092.5 Buildings classification with hierarchical clustering

210 A hierarchical clustering with the heat map visualization technique was used to group

211 buildings that share the similar daily load characteristics. Hierarchical clustering is a bottom-up

212 strategy, which starts with placing each object in its own cluster and then merges the atomic

213 clusters into larger clusters until all objects are in a single cluster [21]. Complete-linkage, which

214 is the maximum ED of the data objectives in two clusters, was used to measure the distance

215 between the clusters.

216 An advantage of the hierarchical clustering is that the overall process can be represented by a

217 tree structure graph called a dendrogram. The dendrogram can help to visualize the cluster

218 structure and assist in determining the optimal number of clusters. Fig. 3 illustrated a dendrogram

219 with three data points, where the ordinate axis indicated the distance between the data

220 points/clusters. The split points indicated the distance between the two data points/clusters. The

221 higher the split point, the less similarity between the data points/clusters [4]. Clusters can be

222 determined by the dashed line shown in Fig. 3, which is a user-defined threshold. The data points

223 under the same split point below the dashed line can be merged into a cluster while the split

224 points above the dashed line are kept unchanged. For instance, the data points \#1 and \#3 were

225 under the same split point and below the dashed line and they will be merged into the same

226 cluster while the data point \#2 formed another cluster. The threshold can be determined

227 graphically or based on the cluster validation index such as Dunn Index. More details of the

228 hierarchical clustering can be found in [21]. 


\section{Performance evaluation of the proposed strategy}

230 In this study, the proposed strategy was implemented in R [22] while PAM algorithm was 231 implemented using the R package cluster [23]. The majority of the figures presented in this study 232 were generated using R package ggplot2 [24].

$233 \quad 3.1$ Description of the case study buildings

234 The performance of the proposed strategy was evaluated based on the heating energy usage 235 data collected from 19 higher education buildings, with a total floor area of approximately $236200,000 \mathrm{~m}^{2}$, at Norwegian University of Science and Technology in Trondheim, Norway. The 237 hourly building operational data were collected through a web-based Energy Monitoring System.

238 Most of these 19 buildings were built before the year 2000, and the buildings built between

2391960 and 1970 accounted for a large part. The energy certificate of the buildings indicated that 240 the U-values of the exterior walls of the majority buildings were in the range of $0.4-0.60 \mathrm{~W} / \mathrm{m}^{2} \mathrm{~K}$, 241 which failed to comply with the current energy efficiency regulations. Table 1 summarizes the 242 major information of the 19 buildings studied. More information on these buildings can be found 243 in [25].

244 The heating demand of these higher education buildings was supplied through a district 245 heating network and each individual building was equipped with a dedicated heating energy 246 usage meter. The three-year hourly heating energy data collected from September to April in 247 2011-2013 were used in this study for performance evaluation of the proposed strategy.

$248 \quad 3.2$ Data pre-processing

249 The generalized ESD test method was first used to detect and remove outliers. Fig. 4 250 illustrates the three-year hourly heating energy usage data collected from building 03 with the 251 outliers identified (i.e. red circles). It can be seen that there is a large variation in the heating 
252 demand annually. The highest heating demand generally occurred in January and February. It

253 should be noted that there was a small heating demand from May to August but this amount of

254 heating demand was significantly lower than that during the main heating period and was

255 therefore not considered in this study.

256 The data were then standardized to zero mean and one standard deviation and transformed to

257 daily segments. After removing the daily load profiles with small variations and daily load

258 profiles in the weekends, a total of 9,062 daily heating energy usage profiles were generated after

259 the completion of the data pre-processing step.

2603.3 Identification of typical daily heating energy usage profiles

261 The number of clusters selected will directly influence the identification of the typical daily

262 load profiles. A too small cluster number might result in meaningless typical daily load profiles

263 while a large cluster number requires a large computational cost and increases the difficulties in

264 the results evaluation and interpretation. In this study, the optimal cluster number $k$ (i.e. the

265 number of the typical daily load profiles) was selected between 5 and 15. Fig. 5 presents Dunn

266 Index calculated when using different numbers of the clusters. It is shown that the highest Dunn

267 Index resulted when the cluster number was 11, which was therefore determined as the optimal

268 cluster number in this study.

269 The boxplot of the aggregated dissimilarity measure of the identified clusters is illustrated in

270 Fig. 6 for visualization and removal of the daily load profiles beyond the threshold. It can be

271 observed that the number of the daily load profiles in all clusters ranged from 474 to 1413 ,

272 indicating that there was no cluster formed with few daily load profiles. It can also be seen that

273 all clusters contained the extreme daily load profiles (i.e. black dots) with the aggregated

274 dissimilarity beyond the threshold (i.e. Q3+1.5IQR) and these extreme daily load profiles were 
275 removed in subsequent analysis. A total of 8,521 daily load profiles remained after removing the

276 identified outlier (i.e. extreme daily load profiles) from the dataset. The removal of this small

277 fraction of the extreme daily load profiles could enhance the visualization of the identified typical

278 daily load profiles without significant loss of the information.

279 Fig. 7 shows the identified typical daily load profiles by averaging all daily load profiles in

280 each cluster after the removal of the extreme daily load profiles. The red curves in the figure

281 showed the typical daily load profiles identified while the gray curves were all corresponding

282 daily load profiles in this cluster. It can be found that there was a clear boundary in the heating

283 demand between the working hours and non-working hours in some typical daily load profiles

284 such as the load profiles 2 and 8 while that in some typical daily load profiles (e.g. the load

285 profiles 1 and 5) were not very clear. There was no obvious boundary in the load profile 10.

286 Moreover, the nighttime from 22:00 to 03:00 of next day was the lowest heating energy usage

287 period for the majority of the typical daily load profiles identified except the typical load profiles

288 6, 7 and 10 with a noticeable high heating demand during the nighttime which is worthwhile for 289 further investigation.

290 Fig. 8 shows the weekday distribution of the building daily load profiles in the identified 291 clusters, in which y-axis represents the percentage of the number of days belongs to each

292 weekday to the total number of days in each cluster. It was shown that the daily load profiles on

293 Tuesday, Wednesday, Thursday and Friday in each cluster were almost evenly distributed. In

294 some clusters such as the clusters 4 and 11, the number of days on Monday was obviously

295 different from that on the other weekdays and the reason behind this is presented in Section 4.

296 Therefore, this weekday load profile distribution can assist in determining whether a specific load

297 profile existed only in some specific days of a week. 
Table 2 summarizes the key characteristics and the estimated high heating demand period of

299 the typical daily load profiles identified. To understand the knowledge and information 300 discovered by the proposed strategy, the profiles with a relatively high demand in the early 301 morning and late night as well as those with clear heating demand peaks and troughs will be 302 further investigated in Section 4. These include the typical daily load profiles 4, 6, 7, 9 and 11.

303 The rest of the typical load profiles were either similar to the typical daily load profiles

304 mentioned above or did not contain interesting characteristics and were therefore not further 305 investigated in this study.

$306 \quad 3.4$ Building classification based on the identified typical daily load profiles

307 In this section, 19 case study buildings were grouped according to the typical daily heating 308 load profiles identified. In order to eliminate the influence from the insignificant profiles, the first 309 two most dominant profiles of each building (see Table 3) were selected as the features for 310 building classification. From Table 3, it can be seen that for some buildings such as buildings 02, 31114 and 17, the most dominant profile accounted for a large proportion of the total number of days 312 remained for the typical daily load profile identification. For instance, 436 days out of 490 of

313 building 02 were in the most dominant profile, demonstrating that the daily load variation of this

314 building was consistent. In contrast, the number of days in the most dominant profiles of some 315 buildings such as building 10 and 15 were relatively small, which indicated that these buildings 316 did not have a consistent daily load profile during the time period investigated (2011-2013).

317 The percentages of the first two most dominant profiles were then used to group the buildings 318 that share the same daily energy usage characteristics based on the hierarchical clustering. Fig. 9 319 presents the dendrogram of building classification results, in which the buildings in the same 320 cluster were marked with the same color. In this study, the threshold (i.e. dashed line in the figure) 
321 was visually selected due to the small number of the data points (i.e. buildings) used. It can be

322 seen that some clusters were formed with a single building while some clusters were formed with

323 several buildings. For instance, building 02 was identified as an individual cluster and buildings

$32401,05,10,11$ and 12 were grouped into one single cluster.

325 In order to better visualize and confirm the clustering results, the number of days belongs to a

326 typical daily load profile of different buildings were plotted as a heat map and are shown in Fig.

327 10. In this figure, the relative proportion $(R P)$ was determined using Eq. (9) and the same order of

328 the building number as illustrated in Fig. 9 was used. It was visually shown that the majority of

329 the buildings had one significant dominant profile.

330

$$
R P=\frac{N_{d}}{N_{d, \max }}
$$

331 where $N_{d}$ stands for the number of days belongs to a typical daily load profile of an individual

332 building and $N_{d, \max }$ stands for the maximum number of days belong to a typical daily load profile

333 of the same building.

\section{$334 \quad$ 4. Interpretation of the identified typical daily load profiles}

335 In order to understand the reasons behind the main characteristics of the typical daily load 336 profiled identified, buildings $02,14,17,08$ and 03 were selected based on the clustering results 337 and used to represent the typical daily load profiles of 4, 6, 7, 9 and 11 presented in Fig. 7, 338 respectively.

3394.1 Building 02 - Typical daily load profile 4

$340 \quad$ Building 02 is an office and laboratory building which was built in 1965. A recent survey 341 indicated that this building was poorly insulated with a $\mathrm{U}$-value of $0.91 \mathrm{~W} / \mathrm{m}^{2} \mathrm{~K}$ for the exterior 342 wall insulation and a U-value of $0.59 \mathrm{~W} / \mathrm{m}^{2} \mathrm{~K}$ for the roof insulation. Different from many other 343 buildings using hot water radiators for space heating, the heating of this building was supplied 
344 through ventilation without using heat recovery. However, the heat recovery has been 345 mandatorily required for decades in Norway in ventilation.

346 Fig. 11(a) shows the heating energy usage of building 02 in the two consecutive days. It was

347 clearly shown that the high heating demand started at 04:00 in the morning, which was consistent 348 with the typical daily load profile 4. However, it was much earlier than the normal building 349 occupied hours. The feedback from the building operator indicated that the occupants in this 350 building continuously complained about the thermal comfort during the morning time. The 351 heating period was therefore extended in order to satisfy the occupant thermal comfort and to 352 provide freezing protection [26].

353 4.2 Building 14 - Typical daily load profile 6

354 Building 14 is a sports center, which was usually operated till midnight. The heating demand 355 of this building in the two consecutive days is illustrated in Fig. 11(b). The major characteristics 356 of the two-day heating demand matched well with that of the typical daily load profile 6. The 357 highest heating demand generally occurred around 19:00. This high heating demand was 358 probably related to the hot water usage for the shower requirement. The water usage data of this 359 building in the same two days are presented in Fig. 12. It was clearly shown that there was a high 360 peak of the water usage at around 19:00, which was in line with the heating energy usage profiles.

361 It was also found that the water usage of this building dropped to zero at 01:00 which also 362 matched with the heating demand variation.

3634.3 Building 17 - Typical daily load profile 7

364 Building 17 is a multi-functional building with offices, educational rooms and laboratories, 365 which was constructed around the year 1996. As shown in Fig. 11(c), the two-day heating load 366 profile of this building was similar to that of the typical daily load profile 7 identified. The high 367 heating demand period lasted till to 23:00. The feedback from the building operator indicated that 
369 requirements.

Building 08 is an old building constructed in 1924 and is also a multi-functional building with offices, educational rooms, and laboratories. A clear peak and a clear trough can be observed in Fig. 11(d) at 05:00 and 21:00 respectively, which were consistent with the

374 information presented in the typical daily load profile 9. The heating demand peak and trough

375 were found to be mainly caused by the sudden change of the supply water temperature. The

376 recorded data showed that the hot water was supplied at about $70^{\circ} \mathrm{C}$ during the daytime and $40^{\circ} \mathrm{C}$

377 during the nighttime. The sudden rise of the supply water temperature in the early morning 378 resulted in the heating demand peak of the building while the sudden drop of the supply water 379 temperature in the nighttime led to the occurrence of the trough in the heating load profile. This 380 relationship between the heating energy usage and the variation in the supply water temperature 381 was also observed in a previous study [27].

382 The building operator was also approached for the reason why the high heating demand 383 started at around 05:00. However, no information on this was recorded. This is probably also due

384 to the poor insulation of the building (i.e. U-value of $1.0 \mathrm{~W} / \mathrm{m}^{2} \mathrm{~K}$ for the exterior wall insulation 385 and $\mathrm{U}$-value of $0.7 \mathrm{~W} / \mathrm{m}^{2} \mathrm{~K}$ for the roof insulation), which might result in a longer pre-heating 386 period before the building was occupied.

388 Building 03 is a mix of offices and laboratories, which was constructed in 1951. The typical 389 daily load profile 11 was very similar to the typical daily load profile 9 . However, in the typical 390 daily load profile identified, there were very few days from Monday. Fig. 11(e) illustrates the 391 heating demand of building 03 in two days of Monday and Tuesday. It was clearly shown that 
there was a heating demand peak at 07:00 and a trough at 17:00 in the daily heating load profile

393 on Tuesday, which matched well with the typical daily load profile 11 . However, on Monday, the

394 heating demand peak occurred at 06:00. This is mainly due to the fact that, during the weekend,

395 the heating system was either not running or running with a lower supply water temperature,

396 resulting in a lower indoor temperature than during the weekdays. In order to achieve a desirable

397 thermal comfort on Monday morning, the building was therefore pre-heated earlier than that

398 during the weekdays.

\section{5. Comparison between the use of ED-based and PCC-based clustering}

400 In this section, the results of using the ED-based and PCC-based clustering were compared 401 and presented. The same data pre-processing used for the PCC-based clustering was performed

402 for the ED-based clustering while the commonly used k-means and ED-based dissimilarity 403 measure were used to replace PAM and PCC-based dissimilarity measure. The optimal number 404 of clusters for the ED-based clustering determined was 10, as shown in Figure 13, which was also 405 determined based on Dunn index.

406 Based on the optimal number of clusters determined, the typical daily heating load profiles 407 can then be identified after removal of the extreme daily load profiles based on the box plot 408 analysis. Fig. 14 presents the clustering results and the identified typical daily heating load 409 profiles using the ED-based clustering. It can be seen that the profiles identified using the k410 means clustering with ED-based dissimilarity measure can still provide some useful information 411 in the identified typical daily heating load profiles. For instance, a morning peak was observed 412 and the building was heated till to midnight in the typical daily load profile 7, which was very 413 similar to the typical daily load profile 6 identified using the proposed strategy.

$414 \quad$ However, some profiles identified such as the typical daily load profiles 3 and 9 were too flat 415 and cannot provide useful information for further analysis. Some important information, e.g. 
416 05:00 heating demand peak (corresponding to the load profile 9 in Fig. 7), 04:00 high heating

417 demand start time (corresponding to the load profile 4 in Fig. 7), 17:00 low trough 418 (corresponding to load profile 11 in Fig. 7), identified by the proposed strategy cannot be

419 identified using the k-means clustering with ED-based dissimilarity measure. In addition, some 420 profiles such as the load profiles $2 \& 7$, and the load profiles $6 \& 8$ presented in Fig. 14 showed

421 very similar trends but with different magnitudes. This further demonstrated that the ED-based

422 dissimilarity measure tends to identify daily load profiles that were similar in terms of the 423 intensity.

424 The heat map in Fig. 15 illustrated the number of days belongs to a typical daily load profile 425 of different buildings when using the ED-based clustering. The order of the buildings in the map 426 was also determined based on the hierarchical clustering. Compared to the results presented in

427 Fig. 10, it was clearly shown that the building heating energy usage cannot be characterized by 428 the most dominant load profiles as there was no clear difference between the number of days 429 belong to the most dominant typical daily load profile and that belongs to the other typical daily 430 load profiles. It was also demonstrated that it is difficult to use the ED-based clustering identified 431 typical daily load profiles for building classification.

\section{6. Conclusions}

433 Understanding multiple buildings energy performance requires advanced data analytics. This 434 paper presented a variation focused Partitioning Around Medoids (PAM) cluster analysis strategy 435 to identify the typical daily load profiles of higher education buildings, in which Pearson 436 Correlation Coefficient was used as the dissimilarity measure to group the daily load profiles on 437 the basis of the variation similarity instead of the magnitude similarity.

438 The performance of the proposed strategy was evaluated using the heating energy usage data 439 of 19 higher education buildings in Norway collected from 2011 to 2013. The results showed that 
440 the proposed strategy can identify and discover the information related to building daily heating 441 energy usage characteristics, including daily high heating demand start time and end time, the 442 peaks, troughs and variations of daily heating energy usage. The results obtained also confirmed

443 the effectiveness of the proposed strategy in identifying the typical daily heating energy usage 444 profiles in terms of the variation similarity.

445 The identified daily heating energy usage characteristics can be used to assist in the 446 development of advanced building control and fault detection \& diagnosis strategies, and cost447 effective demand side management techniques. The information discovered is also useful to 448 support the energy planning and retrofitting of higher education buildings. This method could be 449 adapted to identify the daily energy usage characteristics of other types of buildings.

451 Acknowledgement

452 This research work was made possible through an Endeavour Research Fellowship. The first 453 author would like to thank the support of Australian Government - Department of Education and 454 Training.

455 References

456 [1] Z. Ma, P. Cooper, D. Daly, L. Ledo. Existing building retrofits: Methodology and state-of457 the-art. Energy and buildings. 55 (2012) 889-902.

458 [2] L. Pérez-Lombard, J. Ortiz, C. Pout. A review on buildings energy consumption information. 459 Energy and Buildings. 40 (2008) 394-8.

460 [3] H. Gadd, S. Werner. Heat load patterns in district heating substations. Applied Energy. 108 $461 \quad$ (2013) 176-83.

462 [4] P.R.S. Jota, V.R.B. Silva, F.G. Jota. Building load management using cluster and statistical 463 analyses. International Journal of Electrical Power \& Energy Systems. 33 (2011) 1498-505. 
464 [5] C.M.R. do Carmo, T.H. Christensen. Cluster analysis of residential heat load profiles and the 465 role of technical and household characteristics. Energy and Buildings. 125 (2016) 171-80.

466 [6] A.K. Jain. Data clustering: 50 years beyond K-means. Pattern Recognition Letters. 31 (2010) 467 651-66.

468 [7] C. Flath, D. Nicolay, T. Conte, C. van Dinther, L. Filipova-Neumann. Cluster analysis of 469 smart metering data: An implementation in practice. Business \& Information Systems $470 \quad$ Engineering. 4 (2012) 31-9.

471 [8] C. Miller, Z. Nagy, A. Schlueter. Automated daily pattern filtering of measured building 472 performance data. Automation in Construction. 49 (2015) 1-17.

473 [9] M.P. Fernandes, J.L. Viegas, S.M. Vieira, J.M. Sousa. Analysis of residential natural gas 474 consumers using fuzzy c-means clustering. 2016 IEEE International Conference on Fuzzy 475 Systems (FUZZ). pp. 1484-91.

476 [10] I.P. Panapakidis, T.A. Papadopoulos, G.C. Christoforidis, G.K. Papagiannis. Pattern 477 recognition algorithms for electricity load curve analysis of buildings. Energy and Buildings. 73 478 (2014) 137-45.

479 [11] L. Kaufman, P.J. Rousseeuw. Finding groups in data: An introduction to cluster analysis. 480 John Wiley \& Sons, Inc., Hoboken, New Jersey, USA, 2008.

481 [12] L. Ledo. Energy efficiency and thermal comfort upgrades for higher education buildings. 482 University of Wollongong, PhD thesis, 2015.

483 [13] P.N. Tan, M. Steinbach, V. Kumar. Introduction to data mining. Pearson Addison Wesley, 484 USA, 2006.

485 [14] J.E. Seem. Using intelligent data analysis to detect abnormal energy consumption in 486 buildings. Energy and Buildings. 39 (2007) 52-8. 
[15] C. Fan, F. Xiao, S. Wang. Development of prediction models for next-day building energy

488 consumption and peak power demand using data mining techniques. Applied Energy. 127 (2014) $489 \quad 1-10$.

490 [16] I. Khan, A. Capozzoli, S.P. Corgnati, T. Cerquitelli. Fault detection analysis of building 491 energy consumption using data mining techniques. Energy Procedia. 42 (2013) 557-66.

492 [17] H. Blockeel, L. De Raedt, J. Ramon. Top-down induction of clustering trees. Proceedings of 493 the Fifteenth International Conference on Machine Learning, 1998. pp. 55-63.

494 [18] L. Kaufman, P. Rousseeuw. Clustering by means of medoids. The First International 495 Conference on Statistical Data Analysis based on the L $\mathrm{L}_{1}$-Norm and Related Methods, Neuchatel, 496 Switzerland, 1987.

497 [19] A. Struyf, M. Hubert, P. Rousseeuw. Clustering in an object-oriented environment. Journal 498 of Statistical Software. 1 (1997) 1-30.

499 [20] G. Brock, V. Pihur, S. Datta, S. Datta. clValid: An R package for cluster validation. Journal 500 of Statistical Software. 25 (2008) 1-22.

501 [21] J. Han, M. Kamber, J. Pei. Data mining: Concepts and techniques (Second Edition). Morgan 502 Kaufmann Publishers, USA, 2006.

503 [22] R Development Core Team. R: A language and environment for statistical computing. R 504 Foundation for Statistical Computing, Vienna, Austria, 2008.

505 [23] M. Maechler, P. Rousseeuw, A. Struyf, M. Hubert, K. Hornik. cluster: Cluster analysis 506 basics and extensions. 2015.

507 [24] H. Wickham. ggplot2: Elegant Graphics for Data Analysis. Springer, New York, 2009.

508 [25] J. Guan, N. Nord, S. Chen. Energy planning of university campus building complex: Energy 509 usage and coincidental analysis of individual buildings with a case study. Energy and Buildings. $510124(2016) 99-111$. 
511 [26] N. Nord, M.H. Martin. Freeze protection method in ventilation system using two hydronic

512 circuits. The $12^{\text {th }}$ International Conference on Air Distribution in Rooms, Trondheim, Norway,

5132011.

514 [27] N. Djuric, V. Novakovic, F. Frydenlund. Heating system performance estimation using

515 optimization tool and BEMS data. Energy and Buildings. 40 (2008) 1367-76.

516

517 


\begin{tabular}{cccc|cccc}
\hline $\begin{array}{c}\text { Building } \\
\text { NO. }\end{array}$ & $\begin{array}{c}\text { Construction } \\
\text { year }\end{array}$ & $\begin{array}{c}\text { Main } \\
\text { functions }\end{array}$ & $\begin{array}{c}\text { Floor } \\
\text { area }\left(\mathrm{m}^{2}\right)\end{array}$ & $\begin{array}{c}\text { Building } \\
\text { NO. }\end{array}$ & $\begin{array}{c}\text { Construction } \\
\text { year }\end{array}$ & $\begin{array}{c}\text { Main } \\
\text { function }\end{array}$ & $\begin{array}{c}\text { Floor } \\
\text { area }\left(\mathrm{m}^{2}\right)\end{array}$ \\
\hline 01 & 1962 & O/E/L & 15,026 & 11 & 1968 & $\mathrm{O} / \mathrm{L}$ & 12,861 \\
02 & 1965 & O/L & 3,030 & 12 & 1910 & $\mathrm{O}$ & 3,375 \\
03 & 1951 & O/L & 2,215 & 13 & 1981 & O/E/L & 3,955 \\
04 & 1960 & O/E/L & 7,598 & 14 & 1966 & $\mathrm{~S}$ & 4,046 \\
05 & 1966 & O/E/L & 11,400 & 15 & 1975 & O/E/L & 18,175 \\
06 & 1958 & O/E/L & 12,600 & 16 & 1951 & O/E/L & 5,053 \\
07 & 1965 & O/E/L & 9,168 & 17 & 1996 & O/E/L & 2,476 \\
08 & 1924 & O/E/L & 4,116 & 18 & 2002 & E/L & 4,312 \\
09 & 1960 & O/L & 5,028 & 19 & 2000 & O/E/L & 52,773 \\
10 & 1961 & O/L & 17,936 & & & & \\
\hline
\end{tabular}

\# O: office; E: educational room; L: laboratory; S: sports complex.

520 Table 2 Key characteristics of the identified typical daily heating energy usage profiles

\begin{tabular}{|c|c|c|c|}
\hline $\begin{array}{l}\text { Typical } \\
\text { load } \\
\text { profile } \\
\text { No. }\end{array}$ & $\begin{array}{l}\text { Est. high } \\
\text { heating } \\
\text { demand } \\
\text { period }\end{array}$ & $\begin{array}{l}\text { Weekday load } \\
\text { profile almost } \\
\text { evenly } \\
\text { distributed }\end{array}$ & Main characteristics \\
\hline 1 & $\begin{array}{l}07: 00- \\
15: 00\end{array}$ & Yes & $\begin{array}{l}\text { There was a high heating demand from 07:00 to } 10: 00 \text {. The } \\
\text { heating demand was then gradually decreased till to } 16.00 \text { and } \\
\text { then kept relatively stable. }\end{array}$ \\
\hline 2 & $\begin{array}{l}07: 00- \\
17: 00\end{array}$ & No & $\begin{array}{l}\text { The high heating demand occurred during the office hours. A } \\
\text { clear heating demand peak can be observed at 07:00. }\end{array}$ \\
\hline 3 & $\begin{array}{l}07: 00- \\
18: 00\end{array}$ & No & $\begin{array}{l}\text { There was a clear heating demand peak at } 07: 00 \text { and the } \\
\text { heating demand was then gradually decreased till to 18:00. }\end{array}$ \\
\hline 4 & $\begin{array}{l}04: 00- \\
17: 00\end{array}$ & No & $\begin{array}{l}\text { A high heating demand started at around } 04: 00 \text { and then kept } \\
\text { relatively stable till to 17:00. }\end{array}$ \\
\hline 5 & $\begin{array}{l}07: 00- \\
18: 00\end{array}$ & Yes & $\begin{array}{l}\text { The daily heating demand variations were similar to that of the } \\
\text { typical load profile } 1 \text {. }\end{array}$ \\
\hline 6 & $\begin{array}{l}\text { 09:00- } \\
24: 00\end{array}$ & Yes & $\begin{array}{l}\text { There was a small peak at 06:00. A high heating demand } \\
\text { started at 09:00 and lasted till to the midnight. }\end{array}$ \\
\hline 7 & $\begin{array}{l}\text { 09:00- } \\
23: 00\end{array}$ & Yes & $\begin{array}{l}\text { Similar to the load profile } 6 \text { but the heating demand during the } \\
\text { high heating demand period was more stable. }\end{array}$ \\
\hline 8 & $\begin{array}{l}06: 00- \\
18: 00\end{array}$ & No & $\begin{array}{l}\text { Similar to the load profile } 2 \text {. However, there was a clear trough } \\
\text { at } 19: 00 \text {. }\end{array}$ \\
\hline 9 & $\begin{array}{l}\text { 05:00- } \\
20: 00\end{array}$ & No & $\begin{array}{l}\text { Similar to the load profiles } 2 \text { and } 8 \text { but there was a clear peak } \\
\text { at } 05: 00 \text { and a clear trough at 21:00. }\end{array}$ \\
\hline 10 & Not clear & Yes & $\begin{array}{l}\text { The heating demand during } 24 \text { hours was relatively stable. } \\
\text { However, the demand in the early morning was slightly higher } \\
\text { than the rest of the day. }\end{array}$ \\
\hline 11 & $\begin{array}{l}07: 00- \\
16: 00\end{array}$ & No & $\begin{array}{l}\text { Similar to the load profiles } 2,8 \text { and } 9 \text {. There was a clear } \\
\text { heating demand peak at 07:00 and a clear trough at 17:00. }\end{array}$ \\
\hline
\end{tabular}


Table 3 Summary of the first two most dominant profiles of individual buildings

\begin{tabular}{cccccccc}
\hline \multirow{2}{*}{$\begin{array}{c}\text { Building } \\
\text { No. }\end{array}$} & $\begin{array}{c}\text { Total } \\
\text { number } \\
\text { of days }\end{array}$ & $\begin{array}{c}\text { The most dominant profile } \\
\text { Taily load } \\
\text { drofile No. }\end{array}$ & $\begin{array}{c}\text { Total } \\
\text { days }\end{array}$ & $\begin{array}{c}\text { Percentage } \\
(\%)\end{array}$ & $\begin{array}{c}\text { The } 2^{\text {nd }} \text { most dominant profile } \\
\text { daily load } \\
\text { profile No. }\end{array}$ & $\begin{array}{c}\text { Total } \\
\text { days }\end{array}$ & $\begin{array}{c}\text { Percentage } \\
(\%)\end{array}$ \\
\hline 1 & 457 & 5 & 240 & 53 & 3 & 79 & 17 \\
2 & 490 & 4 & 436 & 89 & 3 & 17 & 3 \\
3 & 486 & 11 & 252 & 52 & 8 & 57 & 12 \\
4 & 458 & 11 & 207 & 45 & 4 & 58 & 13 \\
5 & 436 & 5 & 271 & 62 & 7 & 36 & 8 \\
6 & 437 & 3 & 246 & 56 & 1 & 93 & 21 \\
7 & 471 & 8 & 300 & 64 & 11 & 65 & 14 \\
8 & 471 & 9 & 285 & 61 & 7 & 87 & 18 \\
9 & 448 & 10 & 124 & 28 & 3 & 118 & 26 \\
10 & 439 & 7 & 107 & 24 & 5 & 103 & 23 \\
11 & 471 & 5 & 175 & 37 & 7 & 81 & 17 \\
12 & 371 & 5 & 172 & 46 & 10 & 83 & 22 \\
13 & 449 & 3 & 148 & 33 & 2 & 127 & 28 \\
14 & 495 & 6 & 440 & 89 & 7 & 35 & 7 \\
15 & 382 & 1 & 94 & 25 & 3 & 73 & 19 \\
16 & 486 & 2 & 316 & 65 & 4 & 67 & 14 \\
17 & 480 & 7 & 386 & 80 & 5 & 40 & 8 \\
18 & 367 & 7 & 152 & 41 & 6 & 115 & 31 \\
19 & 427 & 1 & 116 & 27 & 5 & 112 & 26 \\
\hline
\end{tabular}

522

523 


\section{$525 \quad$ Figure Captions}

526 Fig. 1 Outline of the variation focused cluster analysis strategy.

527 Fig. 2 Comparison between the PCC and ED-based dissimilarity measures (a) ED; (b)\&(c) PCC.

528 Fig. 3 Illustration of the dendrogram with three data points.

529 Fig. 4 Illustration of the building heating energy usage and outliers identified - building 03.

530 Fig. 5 Dunn Index calculated for different numbers of the clusters - PCC-based clustering.

531 Fig. 6 Boxplot of the aggregated dissimilarities of the identified clusters.

532 Fig. 7 Typical daily heating load profiles (red) identified using the proposed strategy with all 533 corresponding daily load profiles (gray).

534 Fig. 8 Weekday load profile distribution in different clusters identified.

535 Fig. 9 Dendrogram of building classification results.

536 Fig. 10 Heat map of the typical daily load profiles in different buildings - PCC-based clustering.

537 Fig. 11 Illustrations of the heating energy usage of the buildings in two consecutive days.

538 Fig. 12 Water usage of building 14.

539 Fig. 13 Dunn Index calculated for different numbers of the clusters - ED-based clustering.

540 Fig. 14 Typical daily heating load profiles (red) identified using the ED-based clustering with all 541 corresponding daily load profiles (gray).

542 Fig. 15 Heat map of the typical daily load profiles in different buildings - ED-based clustering. 


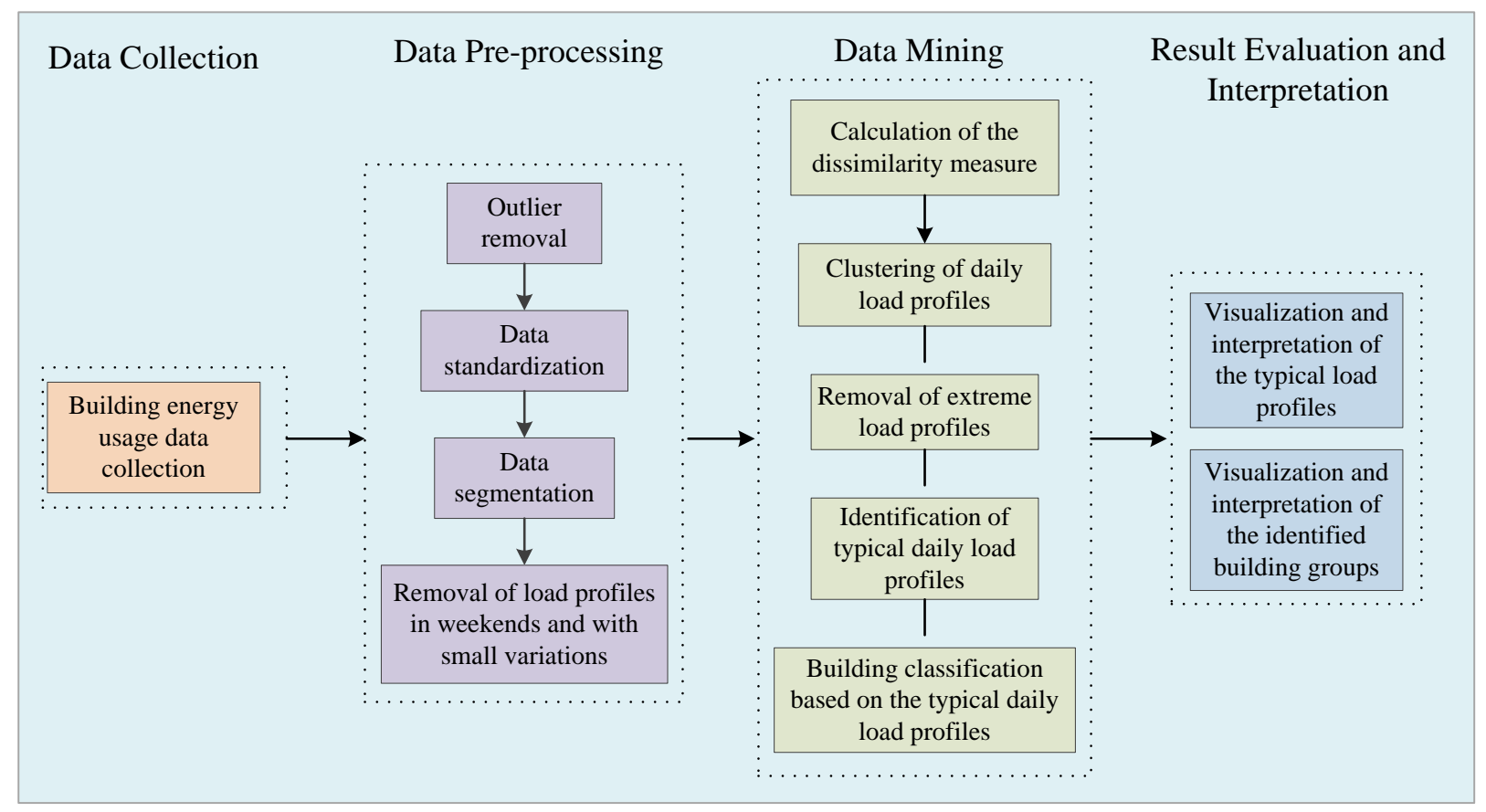

Fig. 1 Outline of the variation focused cluster analysis strategy.

550

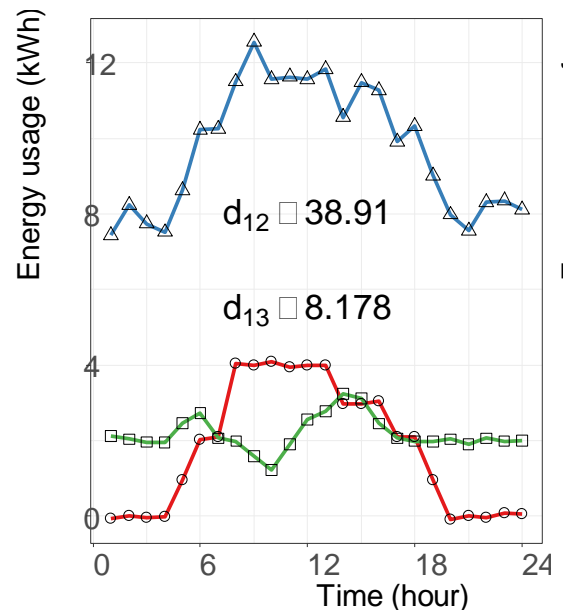

(a)

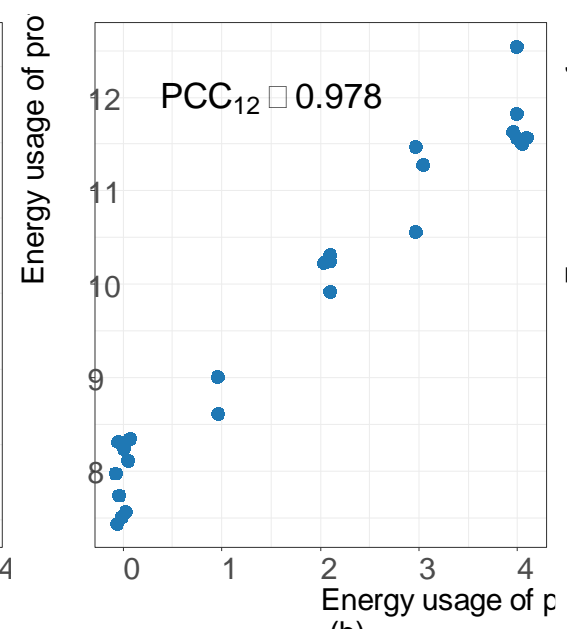

(b)

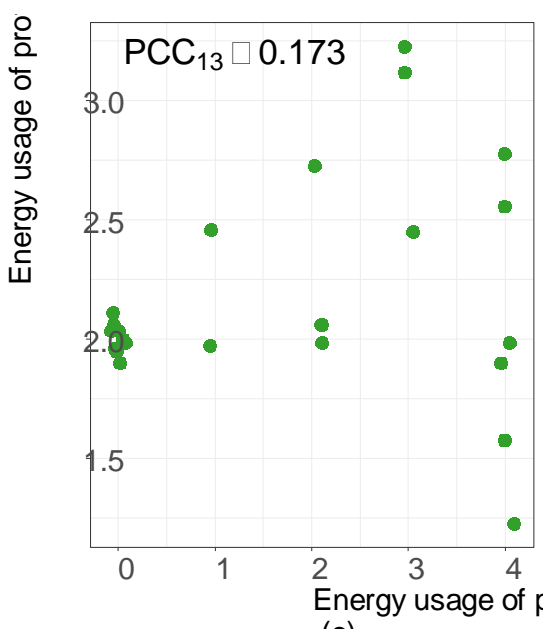

(c)

- Profile 1 vs. Profile 2

552 Fig. 2 Comparison between the PCC and ED-based dissimilarity measures (a) ED; (b)\&(c) PCC. 


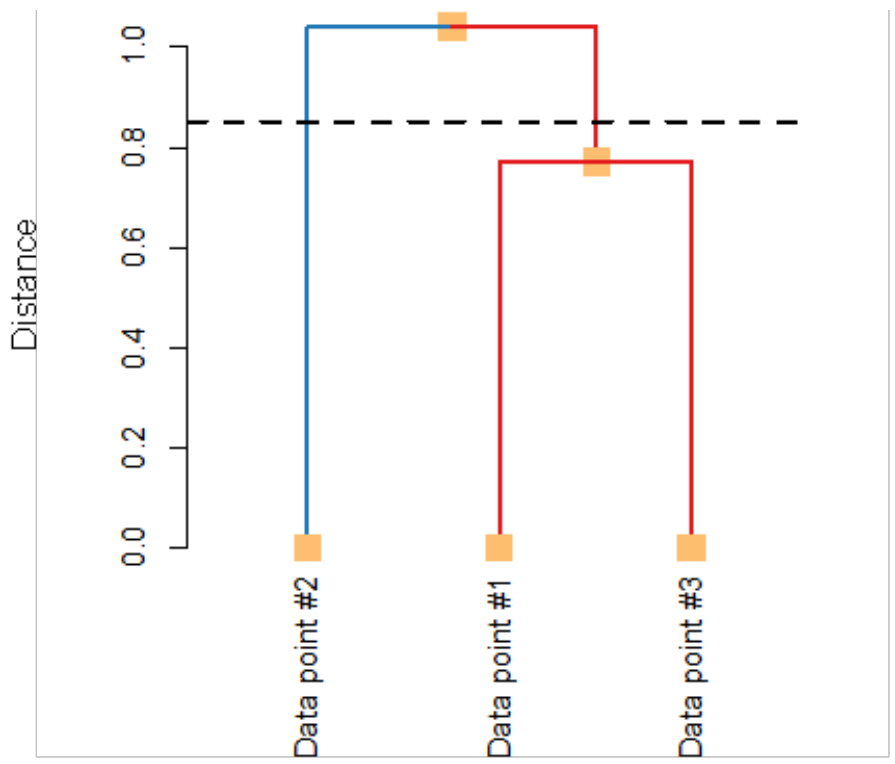

555

Fig. 3 Illustration of the dendrogram with three data points.

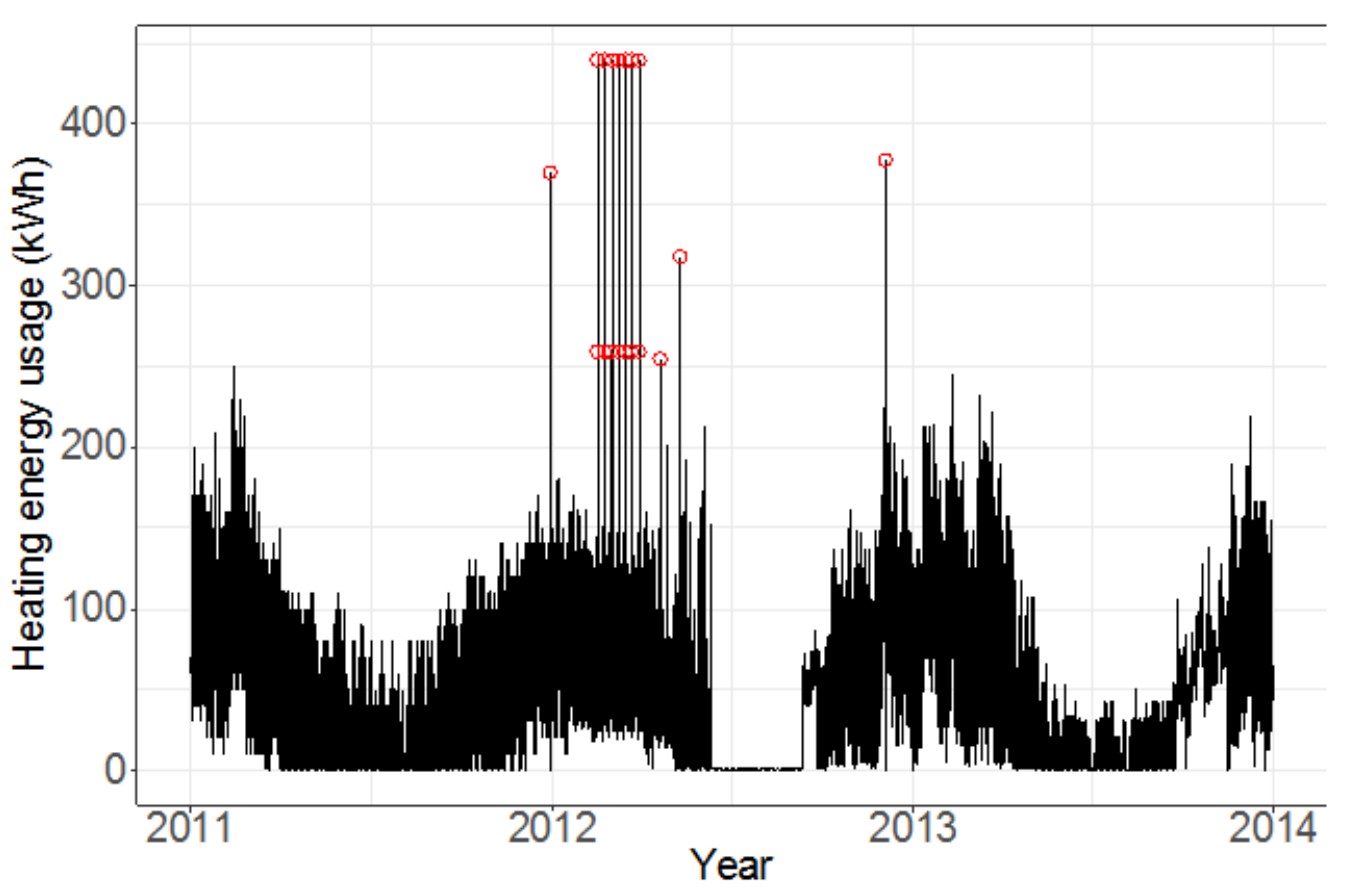

556

Fig. 4 Illustration of the building heating energy usage and outliers identified - building 03. 


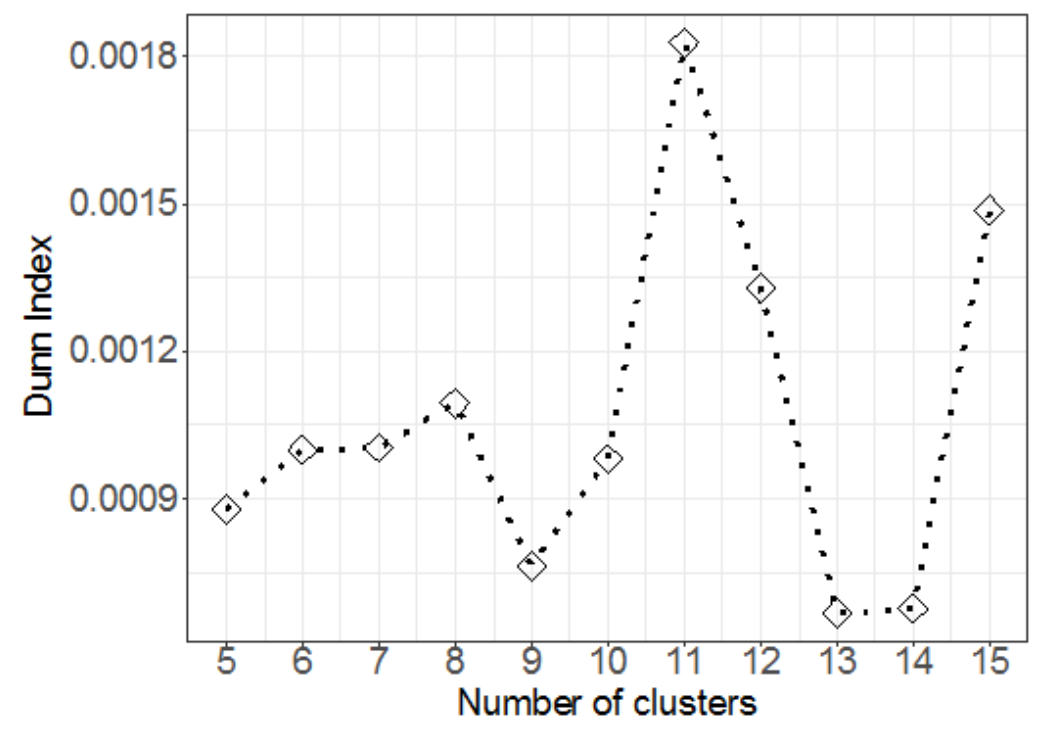

559 Fig. 5 Dunn Index calculated for different numbers of the clusters - PCC-based clustering.

560

561

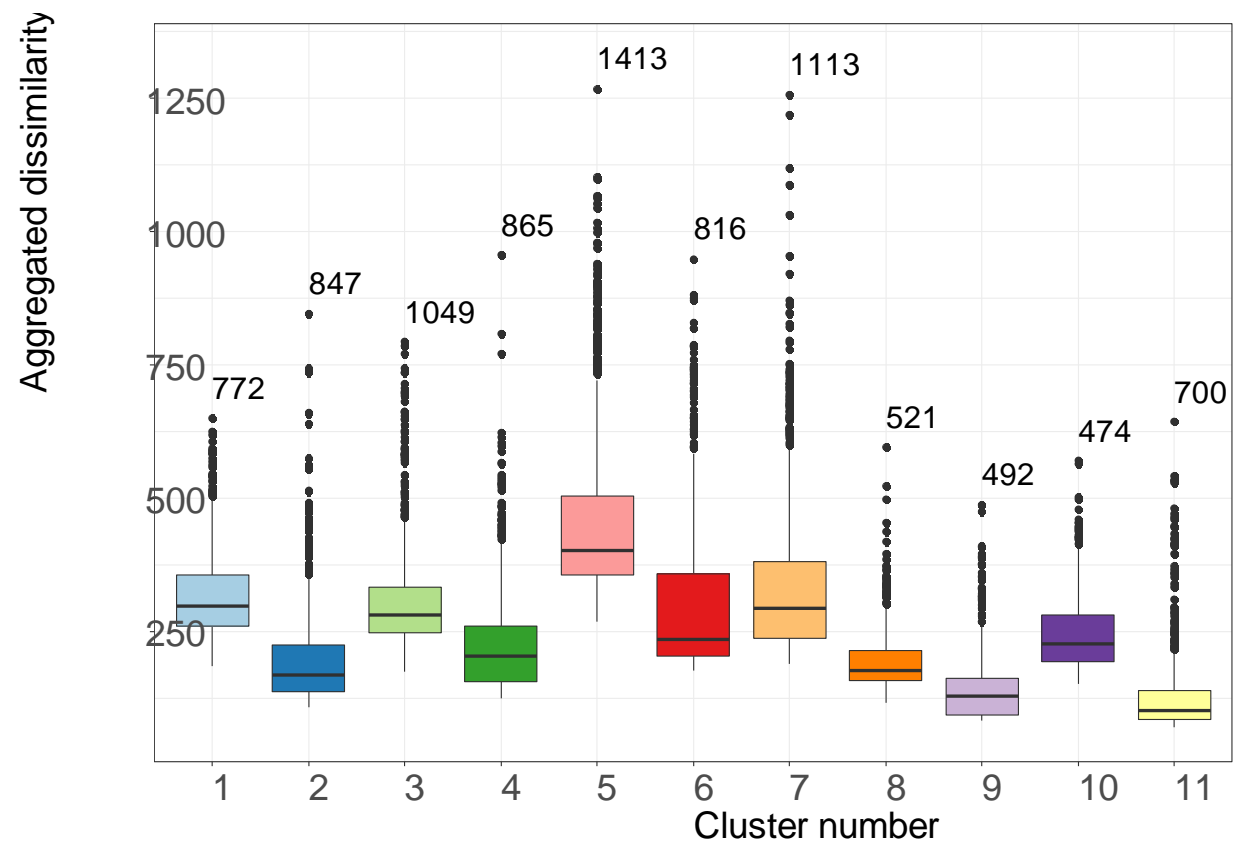

563

Fig. 6 Boxplot of the aggregated dissimilarities of the identified clusters. 

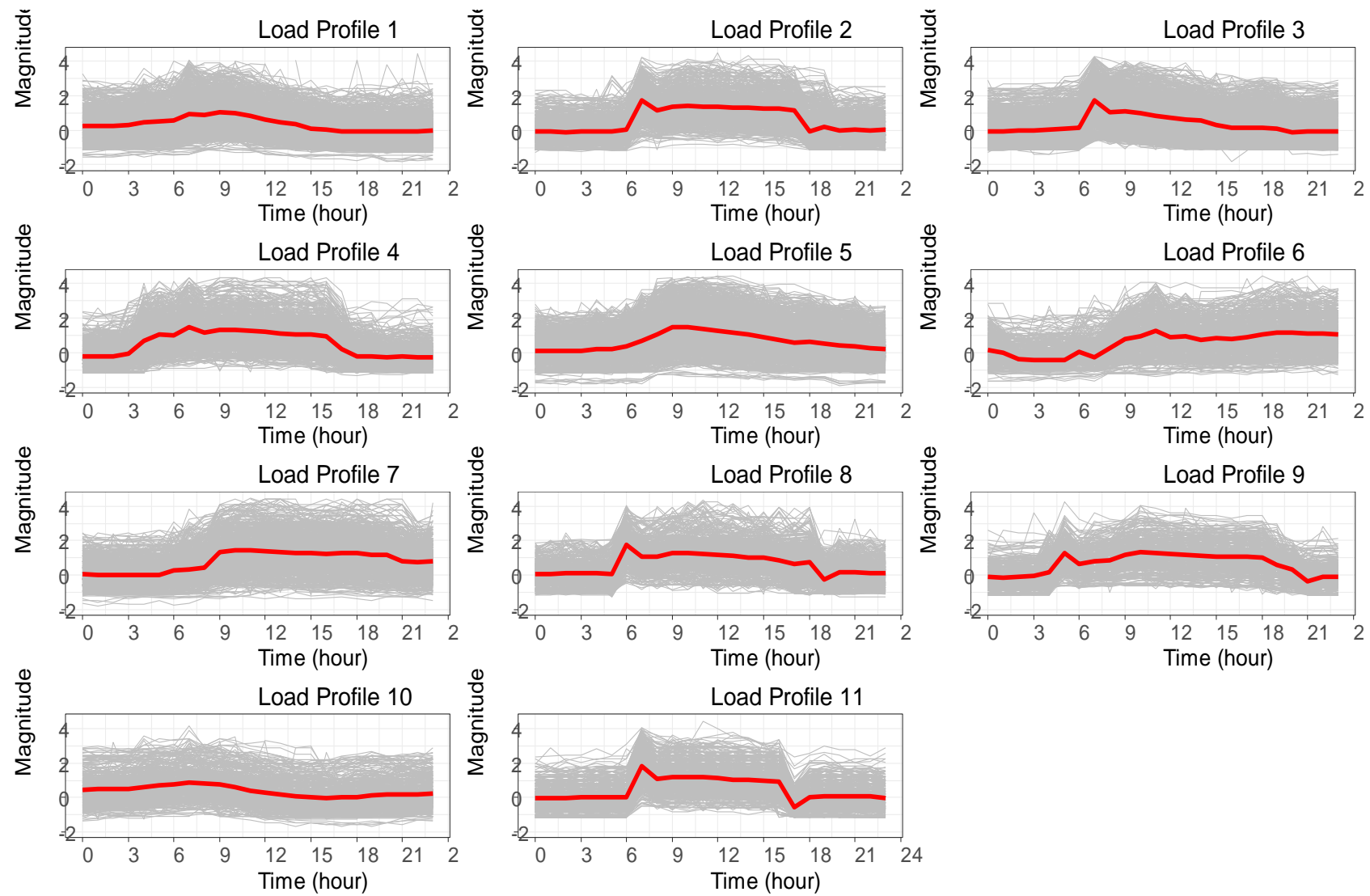

Fig. 7 Typical daily heating load profiles (red) identified using the proposed strategy with all corresponding daily load profiles (gray).

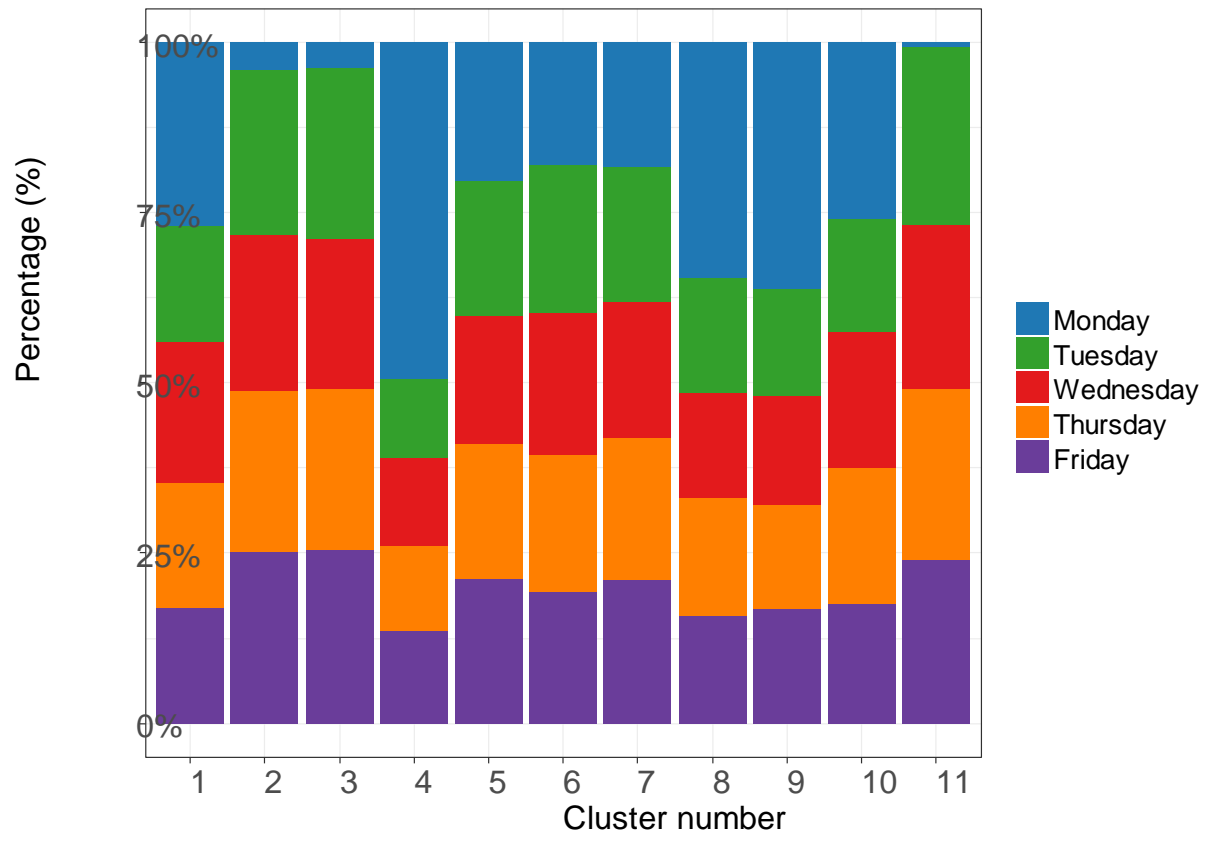

Fig. 8 Weekday load profile distribution in different clusters identified. 


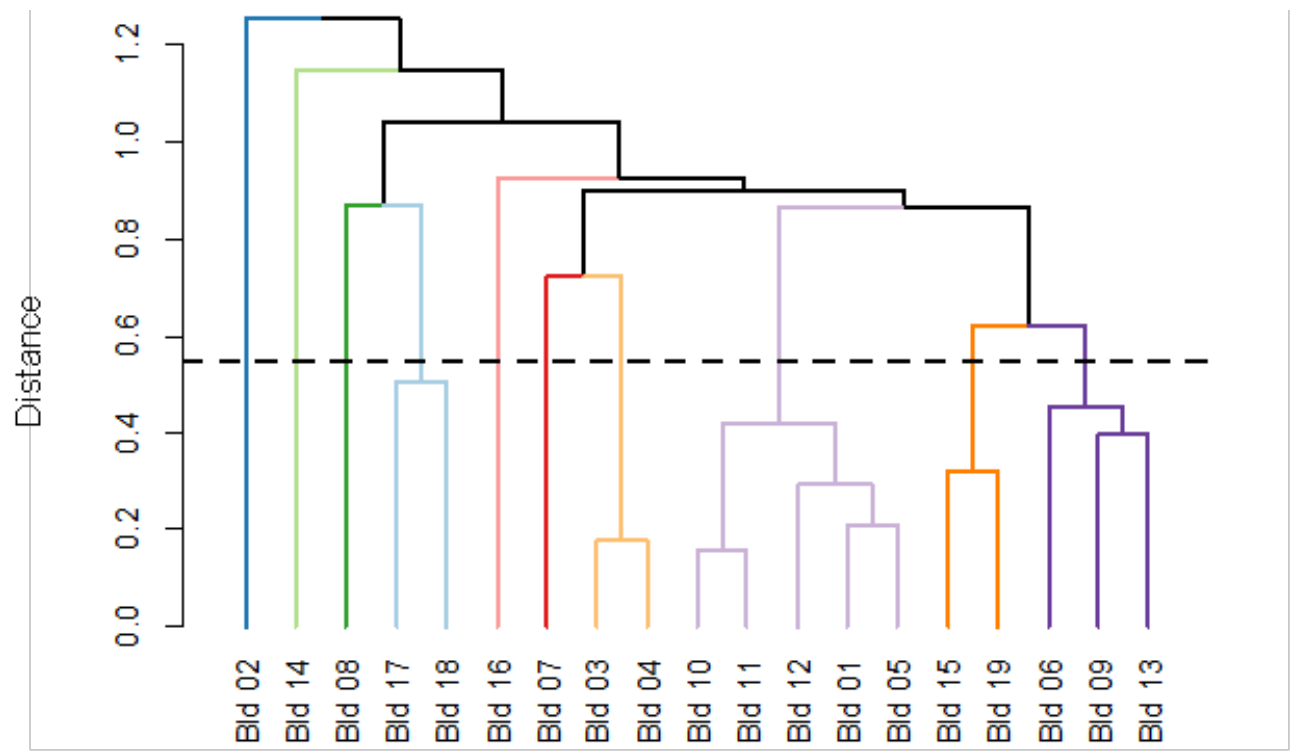

Fig. 9 Dendrogram of building classification results.

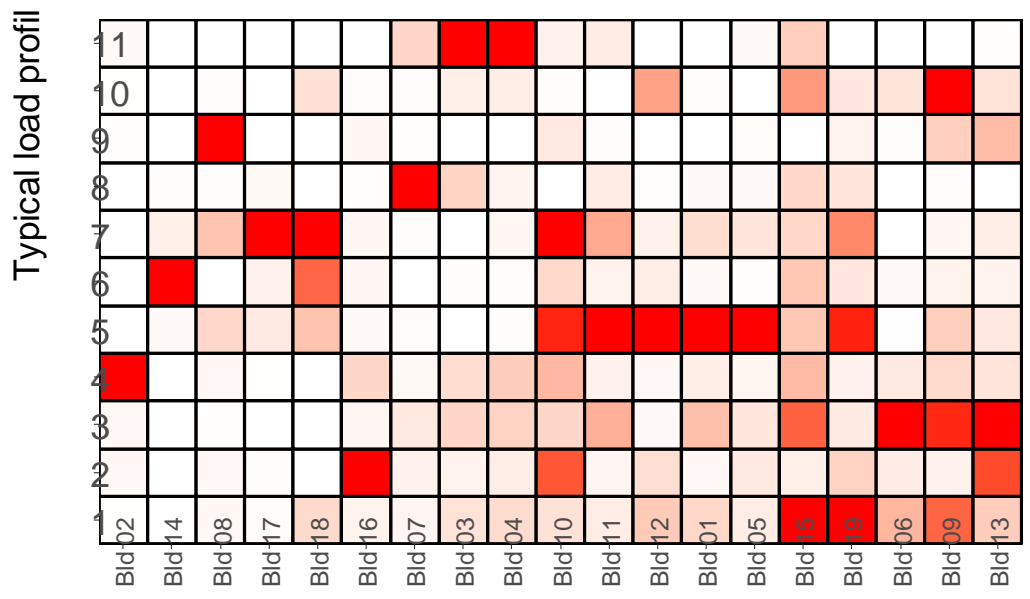

Building number

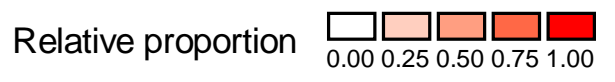

Fig. 10 Heat map of the typical daily load profiles in different buildings - PCC-based 


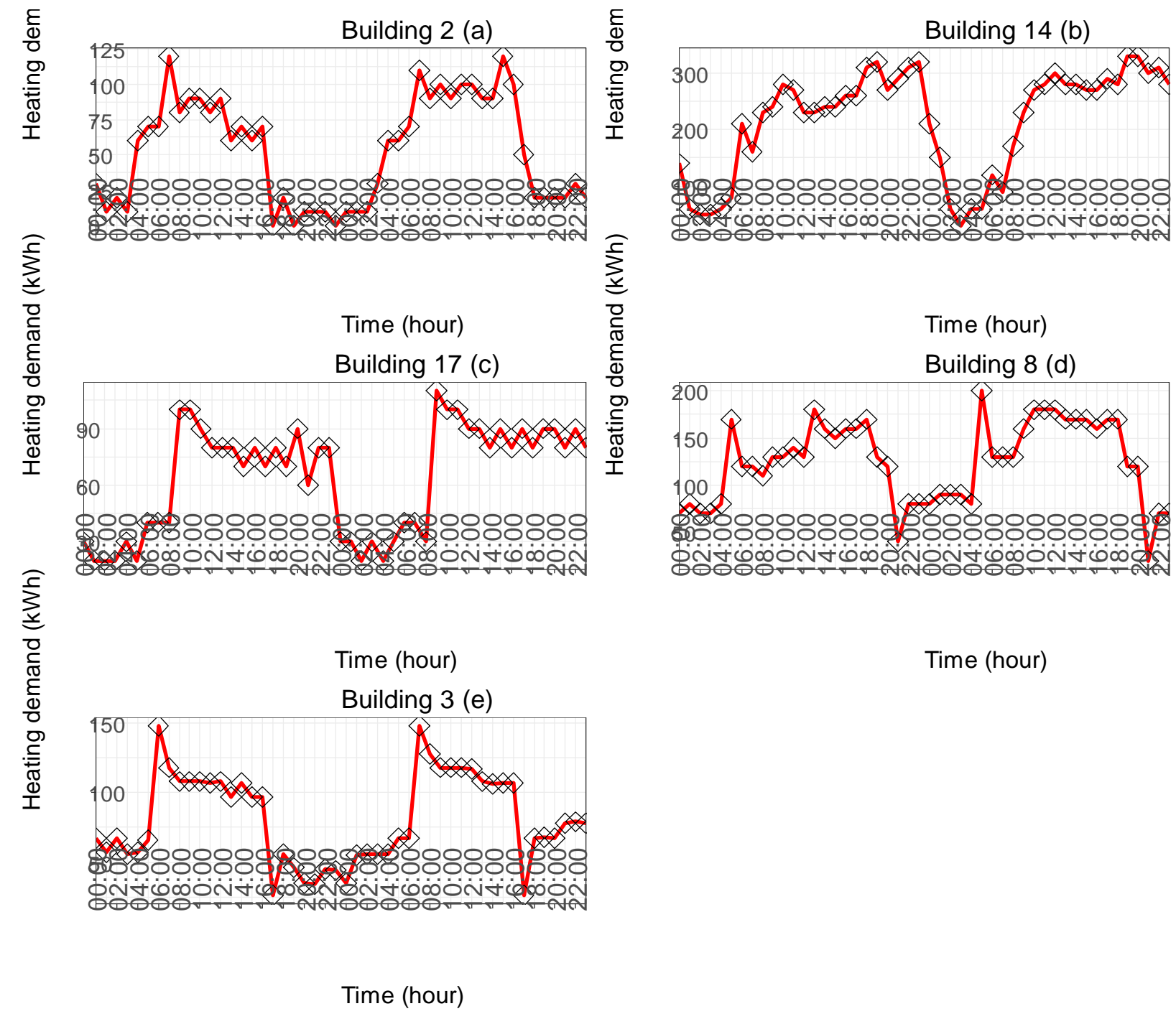
Fig. 11 Illustrations of the heating energy usage of the buildings in two consecutive days. 


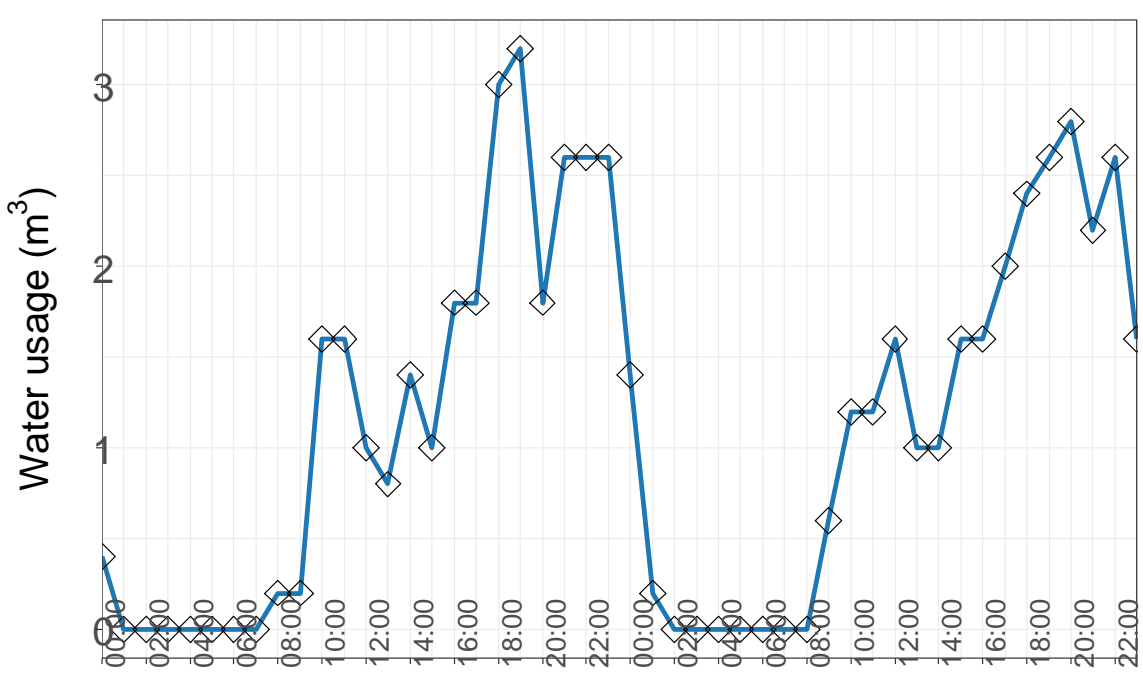

Time (hour)

Fig. 12 Water usage of building 14 .

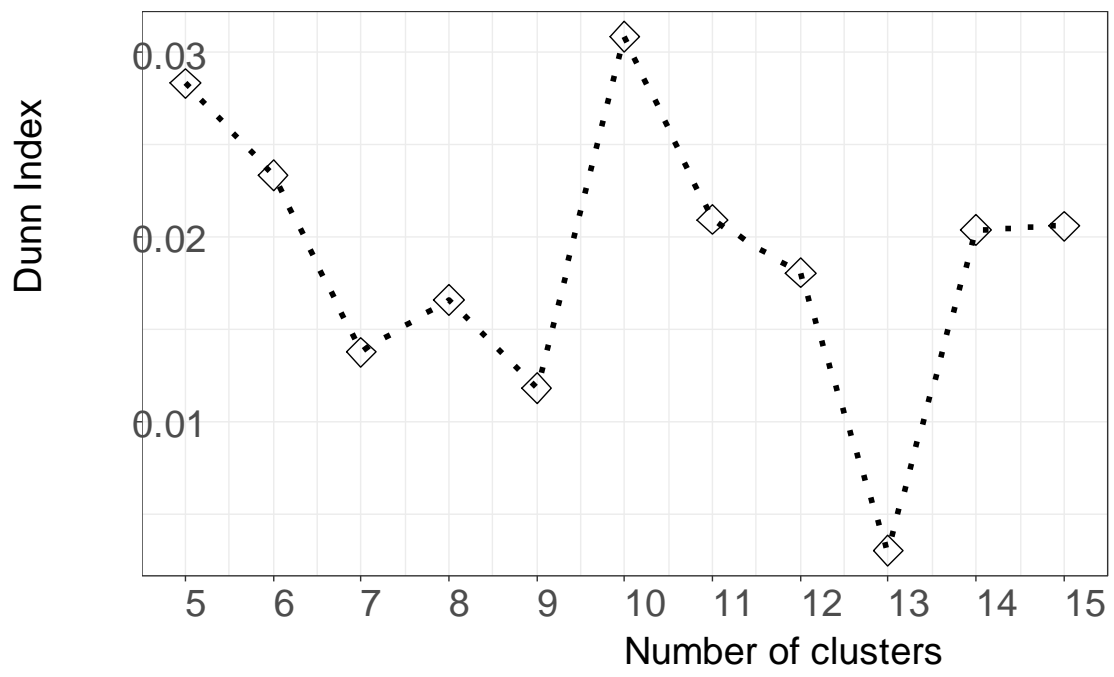

585 Fig. 13 Dunn Index calculated for different numbers of the clusters - ED-based clustering.

586

587

588 

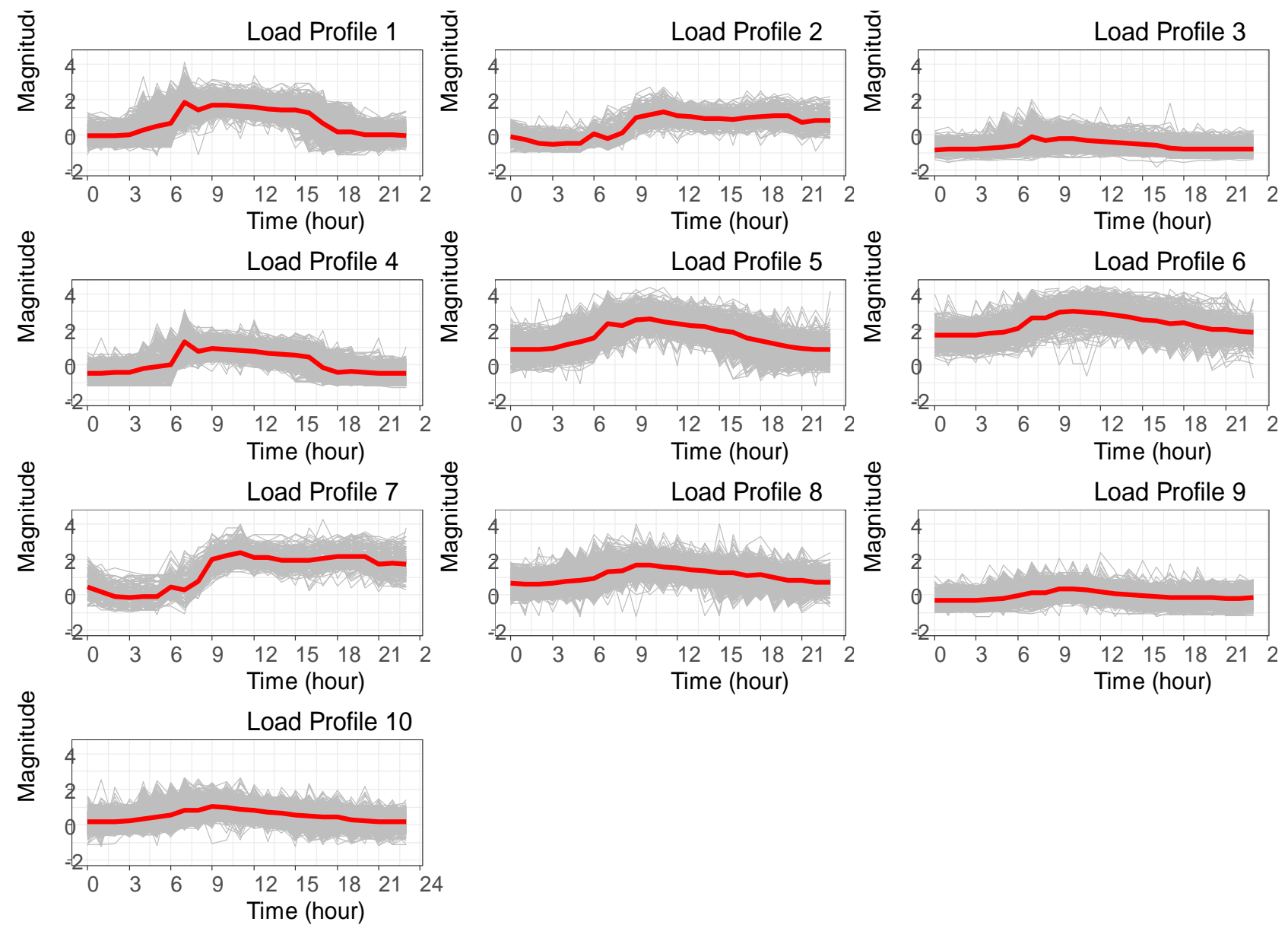

590 Fig. 14 Typical daily heating load profiles (red) identified using the ED-based clustering with all 591 corresponding daily load profiles (gray). 


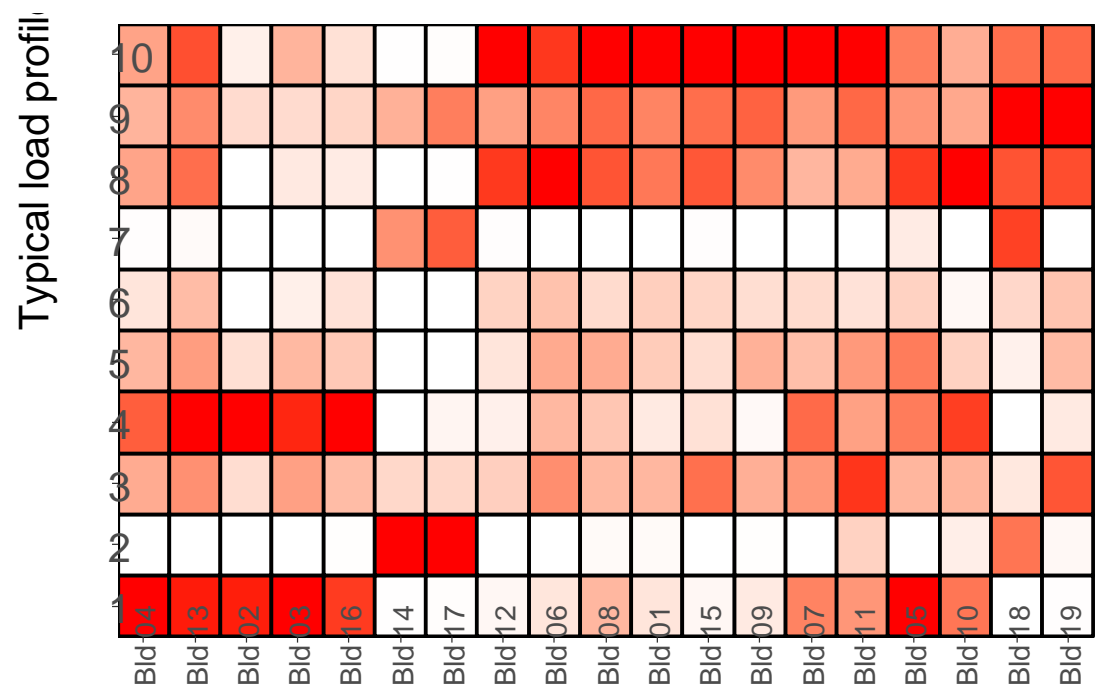

Building number

Fig. 15 Heat map of the typical daily load profiles in different buildings - ED-based clustering. 